\title{
Anti-nutritional factors in canola produced in the Western and Southern Cape areas of South Africa
}

\author{
T.S. Brand ${ }^{1,2 \#}$, N. Smith ${ }^{2}$ and L.C. Hoffman ${ }^{2}$ \\ ${ }^{1}$ Department of Agriculture Western Cape, Private Bag X1, Elsenburg 7607, South Africa \\ ${ }^{2}$ Department Animal Sciences, University of Stellenbosch, Stellenbosch, South Africa
}

\begin{abstract}
The development of low erucic acid, low glucosinolate cultivars of canola seed has led to the availability of a feed ingredient with considerable potential to replace soyabean meal in diets for all classes of farm animals. The sinapine and glucosinolate content of various canola cultivars cultivated in two areas of the Western Cape, South Africa were compared. There were no significant differences in sinapine content between the canola produced in the Western and Southern Cape (mean value of $9.95 \mathrm{mg}$ sinapine/g grain). There were cultivar differences, with Varola 54 and Rainbow cultivars having significantly higher sinapine concentrations than Varola 50. There were no significant differences between the aliphatic, indolyl or aromatic glucosinolate content of the canola originating from either the Swartland or the Rûens areas in South Africa (mean value of $17.84 \mu \mathrm{mol}$ total glucosinolates/g grain). There were significant differences in the total glucosinolate content of the various canola cultivars. Varola 44 and Hylite 200TT had the lowest total glucosinolate concentration and Varola 50 had the highest glucosinolate concentration. The results obtained seem to indicate a maximum dietary inclusion level of up to $14 \%$ for South African produced canola with an average of $17.83 \mu \mathrm{mol}$ glucosinolates per gram to ensure optimal animal production.
\end{abstract}

Keywords: Canola, anti-nutritional factors, sinapine, glucosinolate

${ }^{\#}$ Corresponding author: E-mail: tersb@elsenburg.com

\section{Introduction}

In order to be classified as canola, the oil of rapeseed must contain less than $2 \%$ erucic acid, while the meal must contain less than 30 micromoles of glucosinolates per gram of meal (Thacker, 1990). Prior to the general adoption of the new cultivars of canola, the presence of glucosinolates was the major factor limiting the use of rapeseed meal in pig diets (Bell, 1984). Reduced animal performance, impaired thyroid function in growing animals, foetuses and embryos, and liver haemorrhage mortality in laying hens are the major antinutritive effects of glucosinolates (Campbell \& Schöne, 1998). Although canola meal is an accepted feed ingredient in diets for most poultry, there are a number of reports indicating reduced performance with diets containing significant amounts of this protein supplement (Hulan \& Proudfoot, 1980; Summers \& Leeson, 1985; Leeson et al., 1987).

Rapeseed contains an enzyme called myrosinase, which is capable of breaking down these glucosinolates into a variety of toxic compounds including isothiocyanates, oxazolidinethiones, nitriles and inorganic thiocyanate ion (Paik et al., 1980). Heat is applied in commercial canola processing to condition the seed for improved oil extraction, to inactivate myrosinase and for solvent removal and drying of the meal. The extent of heat treatment is sufficient to cause some thermal degradation of glucosinolates, with indole glucosinolates being more susceptible to degradation than aliphatic glucosinolate (Campbell \& Slominski, 1989). Thermal degradation during commercial seed processing would produce aglucone products similar to those mentioned above but due to the fact that the majority of the aglucone products are extremely reactive and also volatile, there are generally low concentrations in the commercial meal (Campbell \& Schöne, 1998). As progoitrin is the most predominant glucosinolate in most canola varieties, 5vinyloxazolidine-2-thione and the corresponding nitrile, 1-cyano-2-hydroxy-3-butene tend to be the aglucones most often detected in meal (Campbell \& Schöne, 1998). Thiocyanate ion, presumably from the decomposition of the indole glucosinolate, is also a common product in meal. Since myrosinase is usually effectively inactivated during processing, the predominant form of glucosinolates in the meal is intact glucosinolates, even when the moisture content of meal is increased as would occur in the intestinal tract of animals (Campbell \& Schöne, 1998). The glucosinolate in rapeseed meal has long been known to cause 
thyroid dysfunction in pigs. Schöne et al. (1990) studied the goitrogenicity of high glucosinolate rapeseed meal in growing pigs in detail. They varied glucosinolate intake of the pigs by feeding a high glucosinolate meal $(10 \mathrm{mmol} / \mathrm{kg}$ final diet $)$ or a $\mathrm{Cu}$ treated meal $(<1 \mathrm{mmol} / \mathrm{kg}$ final diet $)$ and varied levels of supplemental iodine. Criteria used to assess treatment effects included growth, thyroid weight and total iodine deposition and serum thyroid hormone levels. Growth of the pigs and thyroid size were normalized only by inactivation of glucosinolate $(\mathrm{Cu}$ treated) combined with the administration of iodine.

Schöne et al. (1993) showed that the addition of myrosinase to a high glucosinolate rapeseed meal had a detrimental effect on the thyroid status in young chicks, especially without dietary iodine supplementation. Removal $(\geq 90 \%)$ of glucosinolates from rapeseed meal by treatment with $\mathrm{Cu}$ elevated the anti-thyroid effects, which differed from those of the myrosinase-treated meal with a similar glucosinolate content. In comparing the results of chick experiments to experiments with pigs, Schöne et al. (1993) indicated that chicks were able to tolerate a higher level of dietary glucosinolates. Glucosinolate compounds cause the enlargement of the thyroid gland and inhibit the synthesis and secretion of the thyroid hormones (McKinnon \& Bowland, 1979; Christison \& Laarveld, 1981). These hormones play an essential role in the control of the body's metabolism and if deficient, may reduce the utilization of dietary nutrients causing poor growth and poor reproductive performance (Thacker, 1990). As a result of genetic selection, the glucosinolate content of canola meal has been reduced to about $15 \%$ of the level contained in traditional rapeseed meal (Bell, 1984).

The occurrence of liver haemorrhage mortality among laying hens fed rapeseed meal was first reported by Jackson (1969). This relationship of glucosinolate as a causative agent in liver haemorrhage was confirmed in a study by Campbell \& Slominski (1991) in which hens were fed diets varying in glucosinolate content $(0.2$ up to $3.8 \mathrm{mmol} / \mathrm{kg}$ ) produced by combining low and high glucosinolate meals in varying proportions.

Sinapine is the most common of all phenolic esters in canola seeds. Sinapine is a choline ester of sinapic acid and normally constitutes 1 - 4\% of air-dried oil-free canola meal (Blair \& Reichert, 1984; Uppstrom \& Johansson, 1985). Sinapine is bitter tasting (Blair \& Reichert, 1984) and mainly a constituent of the seed embryo (Bell \& Shires, 1982). Although rarely identified as a detriment for pigs, sinapine may be removed via hydrolysis with ammonia and steam (Bell, 1984). Removal via breeding is a potential area for improvement of canola meal since its competitor, soyabean meal, contains no sinapine (Blair \& Reichert, 1984). Sinapine as a compound in canola meal produces a fishy flavour in the eggs of certain brown-shelled laying strains. Egg taint occurs when sinapine levels exceed $1 \mathrm{~g} / \mathrm{kg}$ diet, and analysis of whole seeds indicated that sinapine levels in canola meal were approximately 6 up to $12 \mathrm{~g} / \mathrm{kg}$. The biochemical mechanism of the egg taint has been reviewed by various authors (Bell 1993; Pokorny \& Reblova, 1995).

Canola has, however, become a popular cash crop in the Western Cape area of South Africa, while approximately $36 \%$ of the total production of canola of 28000 tons per year is used unprocessed as full-fat canola. The remainder (18 000 tons) is available as canola oilcake meal (Brand, 2003). The objective of this study was to quantify the variation in sinapine and glucosinolate content of different cultivars of canola, currently produced in two different locations in the Western Cape.

\section{Materials and Methods}

Twenty canola samples, two per cultivar, were collected at two different locations in the Western Cape, the South-Western Cape (Swartland) and Southern Cape (Rûens) grain producing areas. Samples were analysed using high-pressure liquid chromatography for sinapine and glucosinolate content. The values were then statistically compared for location and cultivar as main factors. The samples were analysed for the aliphatic, the indolyl as well as aromatic glucosinolates. Desulfoglucosinolates were determined as described by Fiebig \& Jörden (1990). The HPLC lines for sinapine were performed according to a modified method of Clausen et al. (1983) under isocratic conditions as described by Clausen et al. (1985). The extraction of sinapine was achieved with 70\% methanol as recommended by Bjerg et al. (1984).

Statistical comparisons, using multifactor analysis of variance techniques were done (Statgraphics, 1991). The main effects tested were location and cultivar.

\section{Results and Discussion}

Statistical analysis on the sinapine content of different canola cultivars produced at two different locations revealed no location by cultivar interaction and results were presented as main effects only. 
Results on the effect of location of production on the sinapine content of the canola are presented in Table 1. Samples originating from the Swartland area tended $(\mathrm{P} \leq 0.08)$ to be lower in sinapine content than the samples originating from the Rûens area of South Africa. Sinapine is concentrated in the embryo of the grain and this phenomenon may be related to the relatively larger seed size and accompanying larger embryo of canola seed originating from the Rûens area, which is probably due to a more favourable climate and soil conditions.

Table 1 Average sinapine content $(\mathrm{mg} / \mathrm{g})$ of canola samples collected from the Swartland and Rûens areas of South Africa

\begin{tabular}{lcc}
\hline Location & Number of Samples & Sinapine content $(\mathrm{mg} / \mathrm{g})$ \\
\hline & 10 & \\
Swartland & 10 & 9.4 \\
Rûens & & 10.5 \\
s.e.m. & & 0.4 \\
\hline
\end{tabular}

There were significant differences between the sinapine contents of the different cultivars (Table 2). Both Varola 54 and Rainbow had significantly higher sinapine concentrations than Varola 50, with the other cultivars falling in between the extremes. Results obtained from cultivars cultivated in South Africa were within the normal ranges of $1-4 \%$ of air-dried oil-free canola meal (Blair \& Reichert, 1984; Uppstrom \& Johansson, 1985) or even lower than the $12-15 \mathrm{~g} / \mathrm{kg}$ in rapeseed meal (Schöne et al., 1997).

Table 2 Average sinapine content ( $\mathrm{mg} / \mathrm{g}$ ) of different canola cultivars cultivated in the Western Cape area of South Africa

\begin{tabular}{lcc}
\hline Cultivar & Number of samples & Sinapine content $(\mathrm{mg} / \mathrm{g})$ \\
\hline Varola 50 & 2 & $7.72^{\mathrm{a}}$ \\
Monty & 2 & $9.04^{\mathrm{ab}}$ \\
Varola 44 & 2 & $9.35^{\mathrm{ab}}$ \\
Insignia & 2 & $9.90^{\mathrm{ab}}$ \\
Scoop & 2 & $10.02^{\mathrm{ab}}$ \\
Hylite 200 TT & 2 & $10.20^{\mathrm{ab}}$ \\
Hyola 60 & 2 & $10.27^{\mathrm{ab}}$ \\
Oscar & 2 & $10.48^{\mathrm{ab}}$ \\
Varola 54 & 2 & $11.11^{\mathrm{b}}$ \\
Rainbow & 2 & $11.53^{\mathrm{b}}$ \\
s.e.m. & 0.89 \\
\hline
\end{tabular}

No significant interaction occurred between the glucosinolate content for the aliphatic glucosinolates, indolyl glucosinolate or aromatic glucosinolates and area of production. Therefore, the results are presented as main effects in Tables 3 and 4.

No significant differences in either the aliphatic, indolyl or aromatic glucosinolate contents of canola produced in the two different areas were observed (Table 3). Similarly no significant difference between different cultivars in either aliphatic, indolyl or aromatic glucosinolates was observed (Table 4). 
Table 3 Average glucosinolate content $(\mu \mathrm{mol} / \mathrm{g})$ of canola samples collected from the Swartland and Rûens area of the Western Cape

\begin{tabular}{lccc}
\hline & Rûens & Swartland & s.e.m. \\
\hline Aliphatic glucosinolates & 14.06 & 14.17 & 0.21 \\
Indolyl glucosinolates & 3.23 & 3.26 & 0.11 \\
Aromatic glucosinolates & 0.45 & 0.50 & 0.07 \\
Total glucosinolates & 17.74 & 17.93 & 0.27 \\
& & \\
a-e Row means with common superscripts do not differ $(\mathrm{P} \leq 0.05)$ &
\end{tabular}

Table 4 Average glucosinolate content $(\mu \mathrm{mol} / \mathrm{g}$ ) of canola samples from the Swartland and Rûens area of the Western Cape area of South Africa

\begin{tabular}{lcccc}
\hline Cultivar & Aliphatic glucosinolates & Indolyl glucosinolates & Aromatic glucosinolates & Total glucosinolates \\
\hline Varola 50 & 14.82 & 3.83 & 0.41 & $19.07^{\mathrm{c}}$ \\
Monty & 14.62 & 3.15 & 0.61 & $18.38^{\mathrm{bc}}$ \\
Varola 44 & 13.28 & 3.23 & 0.35 & $16.87^{\mathrm{a}}$ \\
Insignia & 14.18 & 3.10 & 0.25 & $17.52^{\mathrm{ab}}$ \\
Scoop & 14.41 & 3.26 & 0.73 & $18.40^{\mathrm{bc}}$ \\
Hylite 200 TT & 13.52 & 2.81 & 0.47 & $16.80^{\mathrm{a}}$ \\
Hyola 60 & 13.50 & 3.01 & 0.78 & $17.29^{\mathrm{ab}}$ \\
Oscar & 13.85 & 3.29 & 0.27 & $17.41^{\mathrm{ab}}$ \\
Varola 54 & 14.34 & 3.46 & 0.61 & $18.41^{\mathrm{bc}}$ \\
Rainbow & 14.64 & 3.34 & 0.27 & $18.26^{\mathrm{bc}}$ \\
& & & & 0.4 \\
s.e.m. & 0.35 & 0.22 & 0.09 & \\
\hline
\end{tabular}

${ }^{\mathrm{a}-\mathrm{e}}$ Column means with common superscripts do not differ $(\mathrm{P} \leq 0.05)$

However, differences $(\mathrm{P} \leq 0.05)$ in the total glucosinolate content of the various canola cultivars were observed. Varola 44 and Hylite 200TT had the lowest total glucosinolate concentration and Varola 50 the highest with the other tested cultivars lying between these two concentrations. In a study by Velasco \& Becker (2000) a collection of the genus Brassica was evaluated for total content and profile of seed glucosinolate. The collection similarly contained great variability for glucosinolate content and profile.

Values found for canola cultivated in South Africa were higher than Australian canola cultivars that contain approximately $6.75 \mu \mathrm{mol}$ glucosinolates per gram whole seed (Mailer \& Colton, 1995) or up to 14 $\mu \mathrm{mol} / \mathrm{g}$ (Mullan, 2000). The Canadian Grain Commission (Grain Research Laboratory, Canadian Grain Commission) evaluated the glucosinolate content of canola harvests in Canada and the total glucosinolate content from 1993 to $2003 \mathrm{had}$ a mean value of $12 \mu \mathrm{mol} / \mathrm{g}$. Our study revealed an average total glucosinolate content of $17.8 \mu \mathrm{mol} / \mathrm{g}$, which is higher than these values. However, it is well below the value of $30 \mu \mathrm{mol} / \mathrm{g}$ required for rapeseed to be certified as canola (Brand, 2003).

Glucosinolates per se are not considered toxic. However, their hydrolysed by-products have established goitrogenic and hepatoxic effects. They also tend to have a bitter taste, thus potentially affecting feed intake (Sarwar et al., 1981; Bell \& Shires, 1982; Bourdon \& Aumaitre, 1990) as well as impaired thyroid function in growing animals, foetuses and embryos (Campbell \& Schöne, 1998). These by-products 
are responsible for the decreased performance that affects the utilization or absorption of digestible energy and other nutrients (Yin et al., 1993).

From this study it can be concluded that the location of production in South Africa had no influence on the ANF content of canola. There is some variability in the ANF content between the various cultivars. The variation in ANF's between the cultivars may lead to variation in the production performance of animals fed different canola cultivars. However, there seems to be no danger that canola cultivars used in South Africa will exceed the maximum levels set by the Canola Council of Canada. However, care must be taken on dietary inclusion levels of South African canola to ensure optimum animal production. Depending on the animal species, age and the processing conditions of rapeseed meal, it is recommended that the feed contains no more than $1-2.5 \mu \mathrm{mol}$ glucosinolates per gram of feed (Sorensen, 1988). This indicates a maximum dietary inclusion level of up to $14 \%$ for South African produced canola with an average of $17.83 \mu \mathrm{mol}$ glucosinolates per gram.

\section{References}

Bell, J.M., 1984. Toxic factors in rapeseed meal and progress toward overcoming their effects. J. Anim. Sci. 58, 996-1010.

Bell, J.M., 1993. Factors affecting the nutritive value of canola meal: A review. Can. J. Anim. Sci. 73, 679-697.

Bell, J.M. \& Shires, A., 1982. Composition and digestibility by pigs of hull fractions from rapeseed cultivars with yellow or brown seed coats Brassica campestris, Brassica napus. Can. J. Anim. Sci. 62, 557-565.

Bjerg, B., Olsen, O., Rasmussen, K.W. \& Sorensen, H., 1984. New principles of ion-exchange techniques suitable to sample preparation and group separation of natural products prior to liquid chromatography. J. Liq. Chromatogr. 7, 691-707.

Blair, R. \& Reichert, R.D., 1984. Carbohydrate and phenolic constituents in a comprehensive range of rapeseed and canola fractions: nutritional significance for animals. J. Sci. food. Agric. 35, 9-35.

Bourdon, D. \& Aumaitre, A., 1990. Low-glucosinolate rapeseeds and rapeseed meals: effect of technological treatments on chemical composition, digestible energy content and feeding value for growing pigs. Anim. Feed Sci. Technol. 30, 175-191.

Brand, T.S., 2003. Canola in pig nutrition: A South African perspective. Pig News and Information 24, 27-34.

Campbell, L.D. \& Schöne, F., 1998. Effects of antinutritional factors in rapeseed. In: Proc. $3^{\text {rd }}$ Int. Workshop on 'Antinutritional factors in legume seeds and rapeseed'. EAAP Publication No. 93, 1998.

Campbell, L.D. \& Slominski, B.A., 1989. Extent of thermal decomposition of indole glucosinolates during the processing of canola seed. J. Am. Oil Chem. Soc. 67, 73-75.

Campbell, L.D. \& Slominski, B.A., 1991. Nutritive quality of low-glucosinolate meal for laying hens. Proc. $9^{\text {th }}$ Int. Rapeseed Cong. Vol. 1, 209-211.

Canadian Grain Commission, 2004. Quality of Western Canadian canola, 2003. 1404-303 Main Street, Winnipeg, M.B., Canada.

Christison, G.I. \& Laarveld, B., 1981. Thyroid hormone response to thyrotropin releasing hormone by pigs fed canola, rapeseed or soybean meals. Can. J. Anim. Sci. 61, 1023-1029.

Clausen, S., Larsen, L.M. \& Plöger, A., 1985. Aromatic choline esters in rapeseed. Eds. Sorensen, H., 11, Martinus Nijhoff/Dr. W. Junk Publishers. pp. 61-71.

Clausen, S., Olsen, O. \& Sorensen, H., 1983. Separation of aromatic choline esters by high performance liquid chromatography. J. Chromatogr. 260, 193-199.

Fiebig, H.J. \& Jörden, M., 1990. HPLC of desulfoglucosinolates. J. High Resolution Chromatography \& Chromatography Communications 13, 377-379.

Hulan, H.W. \& Proudfoot, F.G., 1980. The nutritional value of rape seed meal for caged layers. Can. J. Anim. Sci. 60, 139-147.

Jackson, N., 1969. Toxicity of rapeseed meal and its use as a protein supplement in the diet of two hybrid stains of caged lying hens. J. Sci. Food Agric. 20, 734-740.

Kraling, K., Robbelen, G., Thies, W., Herrmann, M. \& Ahmadi, M.R., 1990. Variation of seed glucosinolates in lines of Brassica napus. Plant Breed. 105, 33-39. 
Larson, L.M., Olsen, O., Ploger, A. \& Sorensen, H., 1983. Phenolic choline esters in rapeseed: Possible factors affecting nutritive value and quality of rapeseed meal. Proc. $6^{\text {th }}$ Int. Rapeseed Conf., Paris, 1577-1582.

Leeson, S., Atteh, J.P. \& Summers, J.D., 1987. The replacement value of canola meal for soybean meal in poultry diets. Can. J. Anim. Sci. 67, 151-158.

Mailer, R.J. \& Colton, R.T., 1995. Quality of Australian canola. Canola Association of Australia, Wagga Wagga, NSW, Australia.

McKinnon, P.J. \& Bowland, J.P., 1979. Effects of feeding low and high glucosinolate rapeseed meal and soybean meal on thyroid function of young pigs. Can. J. Anim. Sci. 59, 589-596.

Mullan, B.P., Pluske, J.R., Allen, J. \& Harris, D.J., 2000. Evaluation of Western Australian canola meal for growing pigs. Aust. J. Agric. Res. 51, 547-553.

Paik, I.K., Robblee, A.R. \& Clandinin, D.R., 1980. Products of the hydrolysis of rapeseed glucosinolates. Can. J. Anim. Sci. 60, 481-493.

Pokorny, J. \& Reblova, Z., 1995. Sinapines and other phenolics of Brassicaceae seeds. Potravinarske Vedy. $13(2), 155-168$.

Sarwar, G., Bell, J.M., Sharby, T.F. \& Jones, J.D., 1981. Nutritional evaluation of meals and meal fractions derived from rape and mustard seed. Can. J. Anim. Sci. 61, 719-733.

Schöne, F., Jahreis, R. \& Richter, G., 1993. Evaluation of rapeseed meals in broiler chicks: Effect of iodine supply and glucosinolate degradation by myrosinase or copper. J. Sci. Food Agric. 61, 245-252.

Schöne, F., Jahreis, R., Lange, R., Seffner, W., Groppel, B., Hennig, A. \& Lüdke, H., 1990. Effect of varying glucosinolate and iodine intake via rapeseed meal diets on serum thyroid hormone level and total iodine in the thyroid in growing pigs. Endocrin. Exp. 24, 415-427.

Schöne, F., Groppel, B., Henning, A., Jahreis, G. \& Lange, R., 1997. Rapeseed meals, methimazole, thiocenate and iodine affect growth and thyroid. Investigations into glucosinolate tolerance in pigs. J. Sci. Food Agric. 74, 69-80.

Sorensen, H., 1988. Analysis of glucosinolates and acceptable concentrations of glucosinolates in oilseed rape and products thereof used as feed to different animals. GCIRC Bull. 4, 17-19.

Statgraphic, 1991. Statistical Graphic System (5.0). Statistical Graphic Corporation Inc., 2115 East Jefferson Street, Rockville MD, 20852, 015-033, USA.

Summers, J.D. \& Leeson, S., 1985. Mineral profile of canola and soybean meal. Can. J. Anim. Sci. 65, 913-919.

Thacker, P.A., 1990. Non-traditional Feed Sources for Use in Swine Production. Butterworths, NY, USA.

Uppstrom, B. \& Johansson, M., 1985. Determination of sinapine in rapeseed. J. Swed. Seed Assoc. 95, 123-128.

Velasco, L. \& Becker, H.C., 2000. Variability for seed glucosinolates in a germplasm collection of the genus Brassica. Genet Resources Crop Evol. 47, 231-238.

Yin, Y.L., Chen, C.M., Zhong, H.Y., Huang, R.L. \& Chen, X.S., 1993. Apparent digestibilities of energy, cell wall constituents, crude protein and amino acids of Chinese oil seed meals for growing pigs. Can. J. Anim. Sci. 61, 719-733. 